\section{() OPEN ACCESS}

\title{
Evidence on the efficacy of ivermectin for COVID-19: another story of apples and oranges
}

\author{
Maria Popp $\odot,^{1}$ Peter Kranke, ${ }^{1}$ Patrick Meybohm, ${ }^{1}$ \\ Maria-Inti Metzendorf (1), ${ }^{2}$ Nicole Skoetz (1) , ${ }^{3}$ \\ Miriam S Stegemann, ${ }^{4}$ Stephanie Weibel (i) ${ }^{1}$
}

10.1136/bmjebm-2021-111791

\begin{abstract}
${ }^{1}$ Department of
Anaesthesiology, Intensive Care, Emergency and Pain Medicine, University Hospital Wurzburg, Wurzburg, Bayern, Germany

${ }^{2}$ Institute of General Practice, Heinrich-Heine-Universitat Dusseldorf, Dusseldorf, Germany

${ }^{3}$ Evidence-Based Oncology, Department I of Internal Medicine, Faculty of Medicine and University Hospital Cologne, University of Cologne, Cologne, Germany ${ }^{4}$ Department of Infectious Diseases and Respiratory Medicine, HumboldtUniversitat zu Berlin, Berlin, Germany
\end{abstract}

Correspondence to: Dr Stephanie Weibel, Department of Anaesthesiology, Intensive Care, Emergency and Pain Medicine, University Hospital Wurzburg, 97080 Wurzburg, Germany; weibel_s@ukw.de

Check for updates

( $)$ Author(s) (or their employer(s)) 2021. Re-use permitted under CC BY-NC. No commercial re-use. See rights and permissions. Published by BMJ.

To cite: Popp M, Kranke $P$, Meybohm P, et al. BMJ Evidence-Based Medicine Epub ahead of print: [please include Day Month Year]. doi:10.1136/ bmjebm-2021-111791
The antiparasitic ivermectin has received particular attention as a potential treatment option for COVID-19. Understandably, there is high interest in repurposing an approved inexpensive drug, readily available as an oral formulation. However, Garegnani et al ${ }^{1}$ recently pointed out the proportion of misleading information on ivermectin for COVID-19 published in journals, on preprint servers and websites.

A relevant number of systematic reviews report the use of methodological tools such as assessing bias at study level with the Cochrane Risk of Bias tool or grading the certainty of the evidence following the Grading of Recommendations, Assessment, Development and Evaluation (GRADE) approach, thus suggesting a putative high credibility. Indeed, some published findings seem impressive. A recent meta-analysis by Bryant et al found that ivermectin reduces the risk of death by an average of $62 \%$ (RR $0.38,95 \%$ CI 0.19 to 0.73) compared with no ivermectin in hospitalised patients. $^{2}$

In our Cochrane Review, ${ }^{3}$ we assessed the identical set of trials. However, only 4 of the 15 trials included in Bryant's meta-analysis on mortality met our predefined eligibility criteria, and our conclusion, incorporating careful grading of the certainty of evidence, reveals a less rosy picture. The bottom line demonstrates an important uncertainty whether ivermectin compared with placebo or standard of care reduces or increases mortality in moderately ill hospitalised patients (RR 0.60, 95\% CI 0.14 to 2.51 ; two studies) and mildly ill outpatients (RR 0.33, 95\% CI 0.01 to 8.05; two studies), due to serious risk of bias and imprecision. How do the different assessments come about? The answer lies partly in the baseline data of included studies. Bryant et al pooled heterogeneous patient populations, interventions, comparators and outcomes. In other words, they compare apples and oranges, serving a large bowl of a colourful fruit salad. Usually, pooling of heterogeneous studies increases imprecision of effects in meta-analyses. Why does this not apply to ivermectin? Its alleged effect is driven by studies where the effect size is extremely positive, which has influenced the conclusions in other reviews. One of these studies with a huge effect has now been retracted over ethical concern. ${ }^{4}$
Evidence syntheses must be pieces of the highest trustworthiness. However, reliability is at risk when researchers publish problematic trials or misuse established evidence assessment tools as a guise for quality of evidence synthesis in general, but especially during a pandemic, by trying to create pseudotrustworthiness for substances that cannot be considered effective and safe treatment options nor game changers, at this stage.

Contributors All authors contributed equally to the article. MP and SW wrote the first draft of the article. PK, PM, M-IM, NS and MSS revised the first draft of the article.

Funding The authors received funding for the Cochrane Review on ivermectin from the Federal Ministry of Education and Research, Germany NaFoUniMedCovid19 (funding number: $01 \mathrm{~K} \times 2021$ ); part of the project "CEOsys", which was paid to the institutions.

Competing interests The authors authored the Cochrane Review on ivermectin for preventing and treating COVID-19.

Patient consent for publication Not required.

Provenance and peer review Not commissioned; internally peer reviewed.

Open access This is an open access article distributed in accordance with the Creative Commons Attribution Non Commercial (CC BY-NC 4.0) license, which permits others to distribute, remix, adapt, build upon this work non-commercially, and license their derivative works on different terms, provided the original work is properly cited, appropriate credit is given, any changes made indicated, and the use is noncommercial. See: http://creativecommons.org/ licenses/by-nc/4.0/.

\section{ORCID iDs}

Maria Popp http://orcid.org/0000-0002-1155-3060 Maria-Inti Metzendorf http://orcid.org/00000002-4154-5782

Nicole Skoetz http://orcid.org/0000-0003-47446192

Stephanie Weibel http://orcid.org/0000-00031900-2535

\author{
References \\ 1 Garegnani LI, Madrid E, Meza N. Misleading \\ clinical evidence and systematic reviews on
}


ivermectin for COVID-19. BMJ Evid Based Med 2021. doi:10.1136 bmjebm-2021-111678. [Epub ahead of print: 22 Apr 2021].

2 Bryant A, Lawrie TA, Dowswell T, et al. Ivermectin for prevention and treatment of COVID-19 infection: a systematic review, meta-analysis, and trial sequential analysis to inform clinical guidelines. Am J Ther 2021;28:e434-60.
3 Popp M, Stegemann M, Metzendorf M-I, et al. Ivermectin for preventing and treating COVID-19. Cochrane Database Syst Rev 2021;7:CD015017.

4 Davey M. Huge study supporting ivermectin as Covid treatment withdrawn over ethical concerns. Available: https://www.theguardian. com/science/2021/jul/16/huge-study-supporting-ivermectin-as-covidtreatment-withdrawn-over-ethical-concerns 